\title{
Assessment of Ichthyofaunal Diversity of River Sutlej in District Ludhiana, Punjab (India)
}

\author{
Jitendra Kumar*, Syed Shabih Hassan, Grishma Tewari and Surjya Narayan Datta \\ Department of Fisheries Resource Management, College of Fisheries, Guru Angad Dev Veterinary E Animal Sciences University, \\ Ludhiana, Punjab, INDIA \\ "Corresponding author: J Kumar; E-mail: jitendrafishco@gmail.com
}

Received: 26 Aug., 2020

Revised: 17 Sept., 2020

Accepted: 15 Oct., 2020

\begin{abstract}
The aim of the present paper was to describe the first complete and comprehensive picture on ichthyofaunal diversity of river Sutlej. The findings of the investigation will be an imperative part of the ecological database from river Sutlej. The field data were collected fortnightly from the fish market. The different diversity indices viz., univariate and multivariate analyses were analyzed by PRIMER-E statistical package. A total of 60 species belonging to 43 genera, 17 families and 7 orders were recorded during the investigation. The Margalef richness index (12.14), Shannon-Wiener index (3.871) and Simpson index (0.979) was observed to be highest during Nov. 2019 and seasonally during post-monsoon season. The present study provides a baseline database with respect to fish species diversity for planning effective conservation measures to obtain sustainable fish production.
\end{abstract}

\section{HIGHLIGHTS}

(0) A total of 60 species belonging to 43 genera, 17 families were recorded

(0 The highest diversity was observed during post-monsoon season

( Baseline database will help to obtain sustainable fish production

Keywords: Ichthyofauna, Fish Diversity, Fish Market, River Sutlej, Ludhiana, Punjab

The imperative component of the earth in the existence of life and the most phenomenal component of life is its assorted variety. Biodiversity has been viewed in many ways depending upon the perspectives of people from different spheres. Fishes are the most diversified group among vertebrates, with 33,600 species (Froese and Pauly, 2019) characterized by their diversity in morphology. The river Sutlej water is distributed under the Indus river system and mostly diverted for the canals in Punjab. Around 56 fish species were recorded from Budhha Nullah (a seasonal tributary of river Sutlej) prior to 1964 (Anonymous, 2019) but these days all fishes are wipedout from Budhha Nullah (Jaidka and Hundal, 2016) due to the heavy load of pollution as well as excess toxicity posing serious threat to ichthyofauna of the river (Jaidka and Hundal, 2016). The information on ichthyofauna diversity comprising species abundance, migration and conservation prioritization is lacking for riverine resources of Punjab including river Sutlej. Hence, the present study was commenced to describe the comprehensive picture on ichthyofauna of river Sutlej at district Ludhiana, Punjab. The investigation was also started to make the checklist of ichthyofauna and suggest appropriate measures for the conservation of river Sutlej at Ludhiana.

\section{MATERIALS AND METHODS}

\section{Site selection, sampling methods and data collection}

Tajpur fish market $\left(30^{\circ} 55^{\prime} 8.12 " \mathrm{~N}, 75^{\circ} 54 ' 1.48 ” \mathrm{E}\right)$ and Haibowal fish market (Devnagar) $\left(30^{\circ} 55^{\prime} 05.3 " \mathrm{~N}\right.$,

How to cite this article: Kumar, J., Hassan, S.S., Tewari, G. and Datta, S.N. (2020). Assessment of ichthyofaunal diversity of river Sutlej in District Ludhiana, Punjab (India). J. Anim. Res., 10(5): 783-789.

Source of Support: None; Conflict of Interest: None क्) 
$75^{\circ} 47^{\prime} 29.9^{\prime \prime}$ E) was one of the important fish markets in District Ludhiana and selected for the data collection fortnightly from the fish markets from April 2019 to March 2020. During the field data collection, it was made sure that the fishes accounted were captured from the different stretches of river Sutlej near District Ludhiana and identification was done using taxonomic keys (Froese and Pauly 2019; Jayaram, 1981).

\section{Diversity measurement}

The different diversity indices such as Shannon-Wiener index (H'), Simpson index, Margalef richness index was used to estimate the fish diversity of river Sutlej along its course in Ludhiana. The K- Dominance plot was drawn by ranking the species in decreasing order of abundance to relate the species richness and abundance (Warwick, 1986). Multivariate analysis of the data was used to determine differences in ecological structure between samples. The data were transformed (presence/ absence) before the analysis for multivariate analysis. The computation of matrices of similarities between different pairs of the sample was based on Bray - Curtis similarities measure.

$$
S j k=100\left\{1-\sum_{i=1}^{p}\left(\frac{|Y i j-Y i k|}{(Y i j-Y i k)}\right)\right\}
$$

Non-metric Multi-Dimensional Scaling (MDS) was used to understand the interrelationship between the samples on a map. The MDS stress value indicates the goodness of the fit using the formula:

$$
\text { Stress }=\sum_{j} \sum_{k}(d j k-d j k)^{2} / \sum_{j} \sum_{k} d j k^{2}
$$

The variation in taxonomic distinctness intended for each sample was superimposed on the funnel to find out the deviation from the normal distribution (within the 95\% confidence limit or not). All univariate and multivariate analyses was done by PRIMER-E (Ver. 6.1.6) statistical package (Clarke and Gorley, 2006; Kumar et al., 2020).

\section{RESULTS AND DISCUSSION}

\section{Icthyofauna diversity}

A total of 60 fish species belonging to 7 orders, 17 families and 43 genera were documented throughout the study period. Family Cyprinidae contributed $46.67 \%$ followed by Bagridae (11.67\%), Ambassidae (5.0\%), Channidae $(5.0 \%)$, Mastacembelidae (5.0\%), Notopteridae (3.33\%) to the total fish species whereas other families contributed less than 3.33 percent each (Fig. 1). During the present study, Cyprinus carpio var communis represented highest in order of species abundance followed by Hypophthalmichthys molitrix, Oxygaster gora, Puntius sophore, Rita rita, Xenentodon cancila, Labeo bata, Labeo rohita, Chanda nama and Eutropiichthys vacha. Silver carp and common carp epitomized the exotic component in the fish market and their abundance was observed to be higher compare to other fishes. The other commercially important fishes like Catla, Labeo, Cirrhinus, Channa, Wallago, Sperata, Mystus and other small indigenous fishes were observed in decreasing order of their richness. The occurrence of Labeo pangusia was also observed during monsoon which was not encountered earlier in the fish market at Ludhiana.

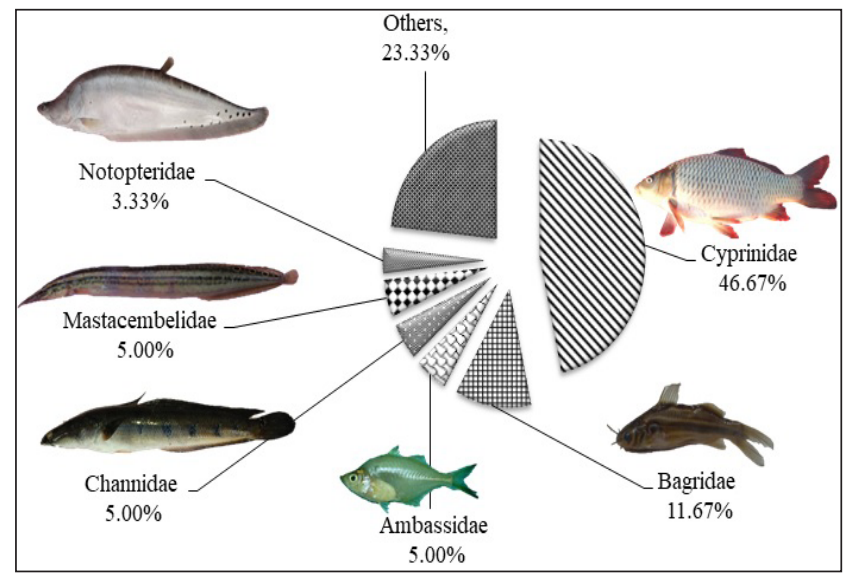

Fig. 1: Pie diagram showing per cent contribution of major families with their representative fish species

Hassan (2016) studied abundance of fishes in river Sutlej and reported 93 fish species with the convergence of a few small tributaries where the river Sutlej water gets augmented at Ludhiana. Kaur et al. (2017) reported 37 fish species in Harike Wetland (downstream part of river Sutlej) and concluded that despite different natural and anthropogenic disturbances the wetland was still supporting species richness. Bhatnagar (2016) reported 59 fish species inhabits the freshwaters of Haryana state and observed decline in fish diversity from 82 species in 
2004 to 59 species in the year 2014. The fish diversity in the present study was less than the earlier reports (Hassan, 2016) which might be attributed to large areas covered in earlier studies. Earlier 116 species of fish were documented from the reorganized Punjab (Johal and Tandon, 1980) but after that 26 and 16 species were investigated from Harike wetland (Dhillon and Kaur, 1996), 37 fish species documented by Kaur et al. (2017).

\section{Diversity indices}

In the present investigation of different indices was used for relating the relationship and describe species abundance in the community. The value of Margalef richness index (d) ranged from 4.42 to 12.14 and the highest was recorded during Nov. 2019 (12.14). The Shannon-Wiener index (H') was between 2.996 to 3.871 and highest was recorded during Nov. 2019 (3.871) which probably that most widely used in ecological studies and the value usually found to fall between 1.5 and 3.5 and only rarely it surpasses 4.5 . The highest value of Simpson index $(\lambda)$ was recorded during Nov. 2019 (0.979) (Table 1).

Table 1: Month-wise variation in different indices based on species abundance

\begin{tabular}{lllll}
\hline & N & d & H'(loge) & 1-Lambda \\
\hline Apr. 2019 & 23 & 7.01 & 3.135 & 0.957 \\
May. & 22 & 6.79 & 3.091 & 0.955 \\
Jun. & 17 & 5.64 & 2.833 & 0.941 \\
Jul. & 34 & 9.35 & 3.526 & 0.971 \\
Aug. & 12 & 4.42 & 2.485 & 0.917 \\
Sep. & 31 & 8.73 & 3.434 & 0.968 \\
Oct. & 36 & 9.76 & 3.584 & 0.972 \\
Nov. & 48 & 12.14 & 3.871 & 0.979 \\
Dec. & 41 & 10.77 & 3.714 & 0.976 \\
Jan.2020 & 40 & 10.57 & 3.689 & 0.975 \\
Feb. & 38 & 10.17 & 3.638 & 0.974 \\
Mar. & 20 & 6.34 & 2.996 & 0.950 \\
\hline
\end{tabular}

Post-monsoon season was observed with occurrence of higher fish assemblage followed by monsoon and premonsoon season (Table 2). The correlation values from the draftsman plot showed Margalef richness index hold positive correlation with $\mathrm{H}^{\prime}$ and $\lambda$ diversity indices (Fig. 2).
Table 2: Seasonal variation in different indices based on species abundance

\begin{tabular}{llllll}
\hline & S & d & J' & H'(loge) & 1-Lambda \\
$\begin{array}{l}\text { Pre } \\
\text { monsoon }\end{array}$ & 31 & 9.932 & 0.979 & 3.360 & 0.963 \\
$\begin{array}{l}\text { Monsoon } \\
\begin{array}{l}\text { Post } \\
\text { monsoon }\end{array}\end{array}$ & 58 & 14.067 & 0.981 & 3.796 & 0.976 \\
\hline
\end{tabular}

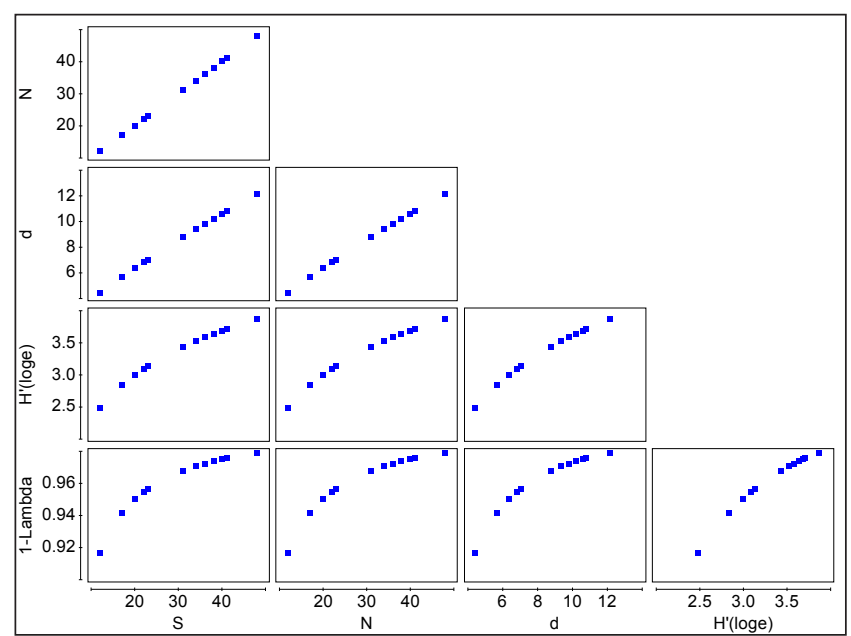

Fig. 2: Draftsman plot showing correlation between indices

\section{K-dominance curve}

The K-dominance cumulative curve expressed as the percentage of abundance in the sample reveal that curve for month Nov. 2019 lies on the lower side and rise slowly due to high species richness (Fig. 3).

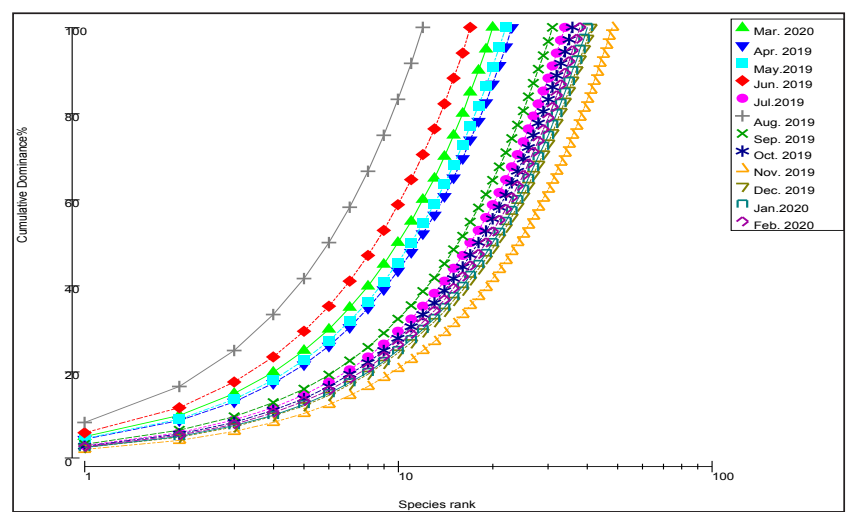

Fig. 3: Month wise K-dominance curve for species biomass 
In relation to the seasonal and community parameters, the total species abundance showed a major peak during post-monsoon season (Fig. 4) which might be due to the cumulative effect of lotic water fishes synchronize nesting activity and migrate upstream during heavy rainfall (monsoon season) and move back after monsoon season (Dudgeon, 1992).

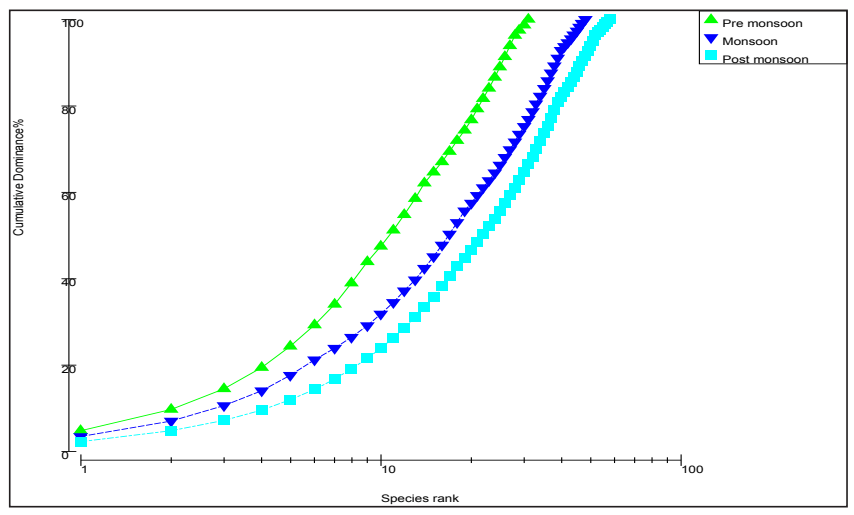

Fig. 4: Seasonal K-dominance curve for species biomass

The lesser species richness observed during the monsoon season which might be due to extreme floodplain siltation, alters habitations affecting species disappearance. Floods link rivers with floodplains and supply nutrients, organic matter to aquatic-terrestrial transition zones, stimulating biological productivity and habitat heterogeneity (Junk, 1989). The species richness increases after floods as riverfloodplain connectivity augments habitat and resource availability (Junk, Bayley, and Sparks, 1989). Since there were heavy rains created a flood-like situation during Aug. 2019 in Ludhiana (The Hindu, 2019) inundated in the nearby areas of temporary lentic water bodies which provide sheltering of fishes and become suitable habitat for their good nourishment, temperature and breeding ground. Since, the lentic water body having abundant nutrient support in the recruitment of small size short distance migratory fishes. The majority of species exhibited greater relative abundance after the flood-like situation (Andrew et al., 2016) and an increase in fishing intensity during post-monsoon may also be one of the reasons.

$\mathrm{K}$-dominance curve rank species in order of importance on the $\mathrm{x}$-axis and show the percentage of each species on the total numbers or biomass on a cumulative scale (called percentage dominance) on the y-axis. To compare the biodiversity between the months, dominance plot drawn by ranking the species in decreasing order of abundance. The K-dominance curve for Nov. month lie on the lower side extended further and rise slowly due to high species richness.

$\mathrm{K}$-dominance curve rank species in order to compare the biodiversity between the seasons, dominance plot drawn by ranking the species. The curve for the post monsoon season lies on the lower side and rise slowly due to more number of species.

\section{CLUSTER ANALYSIS}

The results from hierarchical clustering from overall cluster analysis witnessed that the extreme resemblance in species abundance (78.48\%) was noticed between the month Feb. 2020 and Dec. 2019 and minimum interrelationship between Feb. 2020 and Aug. 2019 (28.00\%) (Table 3 and Fig. 5, 6).

Table 3: Bray-Curtis similarity matrix between months

\begin{tabular}{|c|c|c|c|c|c|c|c|c|c|c|c|c|}
\hline & Mar. & Apr. & May. & Jun. & Jul. & Aug. & Sep. & Oct. & Nov. & Dec. & Jan. & Feb. \\
\hline \multicolumn{13}{|l|}{ Mar. } \\
\hline Apr. & 69.77 & & & & & & & & & & & \\
\hline May. & 66.67 & 75.56 & & & & & & & & & & \\
\hline Jun. & 70.27 & 55.00 & 66.67 & & & & & & & & & \\
\hline Jul. & 55.56 & 56.14 & 57.14 & 50.98 & & & & & & & & \\
\hline Aug. & 43.75 & 40.00 & 41.18 & 41.38 & 39.13 & & & & & & & \\
\hline Sep. & 31.37 & 44.44 & 37.74 & 41.67 & 64.62 & 41.86 & & & & & & \\
\hline Oct. & 53.57 & 54.24 & 55.17 & 45.28 & 71.43 & 37.50 & 68.66 & & & & & \\
\hline Nov. & 50.00 & 59.16 & 60.00 & 43.08 & 70.73 & 36.67 & 60.76 & 66.67 & & & & \\
\hline Dec. & 42.62 & 53.13 & 57.14 & 41.38 & 72.00 & 33.96 & 61.11 & 59.74 & 76.40 & & & \\
\hline Jan. & 50.00 & 47.62 & 45.16 & 35.09 & 67.57 & 38.46 & 50.70 & 63.16 & 75.00 & 66.67 & & \\
\hline Feb. & 34.48 & 45.90 & 53.33 & 36.36 & 66.67 & 28.00 & 66.67 & 67.57 & 74.42 & 78.48 & 69.23 & \\
\hline
\end{tabular}




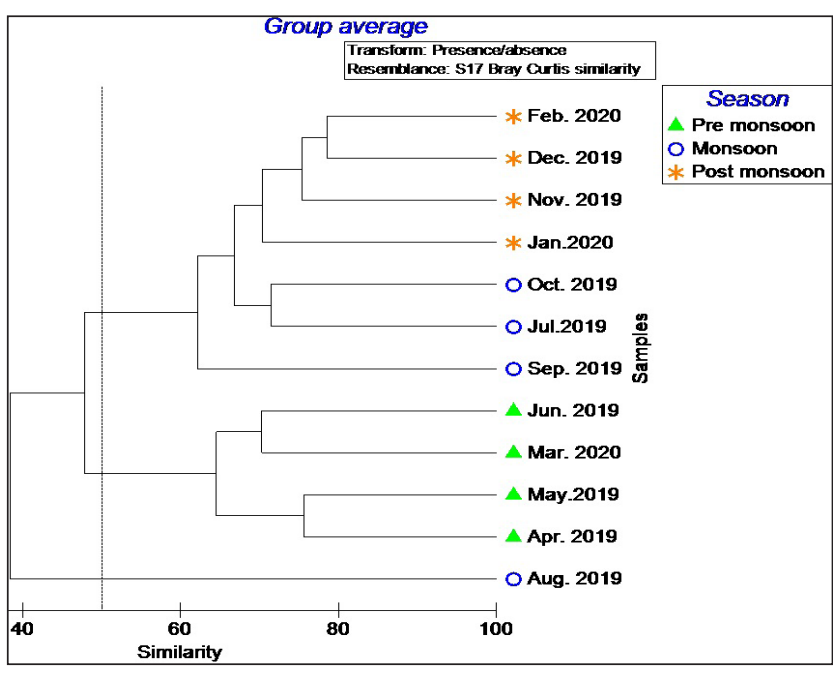

Fig. 5: Hierarchical clustering from Bray-Curtis similarity matrix with group average linking

Cluster analysis of the species similarity matrix was applied to define species assemblage i.e. group of species that tend to occur in a parallel manner across the sites and which can be partitioned into groups with similar community structure. This approach was recommendable because it makes sure the similarity in species composition based on the abundance. The computation of matrices of similarities between different months was based on Bray Curtis similarities measure.

\section{Non-metric Multi-Dimensional Scaling (MDS)}

The samples from neighboring months showed greater similarity in species resemblance. The pre-monsoon and post-monsoon season formed two distinct groups showing a greater degree of similarity in the species composition $(60 \%)$ within the groups and the samples collected during monsoon showed $40 \%$ similarity with the two segregated samples groups within pre-monsoon season. The stress value (0.1), which was superimposed on the MDS plot showed a greater degree of ordination in the collected samples (Fig. 7).

The results of the present study showed that samples from adjacent months have more similarities in species abundance than samples separated over a period. Figure 4 also showed 20 percent similarity in the species abundance during Aug. 2019 for the monsoon season as revealed by MDS plot. During the Aug month only 12 species reported out of 60 due to fishing intensity was very low. This was

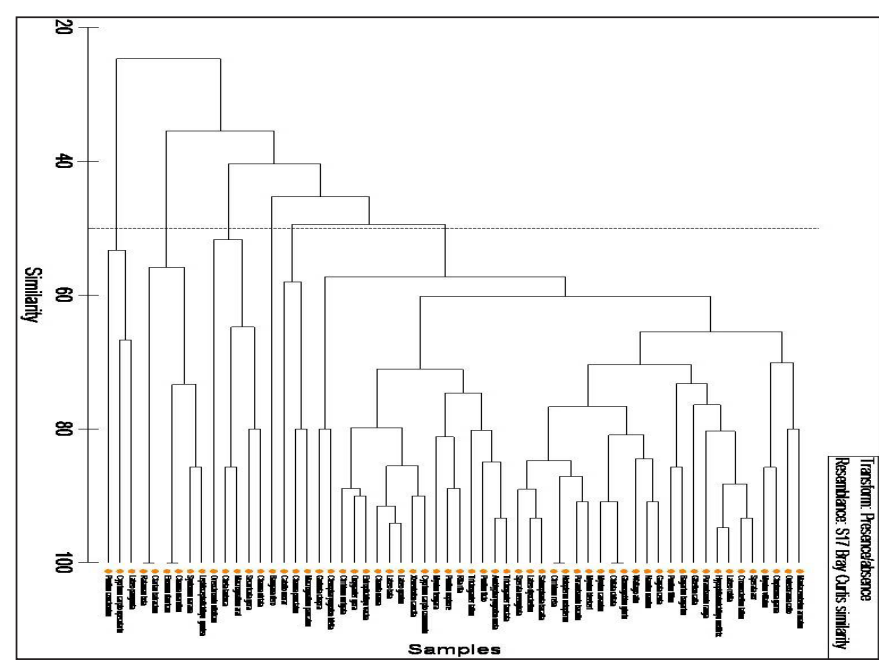

Fig. 6: Hierarchical clustering from Bray-Curtis similarity matrix with group average linking

due to the flood-like situation in Ludhiana following heavy rains and the discharge of excessive water from the Bhakra Dam (The Hindu, 2019). The Sutlej River was flowing near the danger mark. Most of the fishermen did not prefer to install indigenous boats and operate net, gears and tackles during the high current inflow of water. An advisory was issued to the riparian population and fishermen living near the river Sutlej for not to go for fishing during flood and high volume of river water (Indiatoday, 2019). Many researchers have investigated the ichthyofauna of river Sutlej and associated tributaries. A complete picture of the ichthyofauna diversity and spatial distribution outline in the river system still needs more attention.

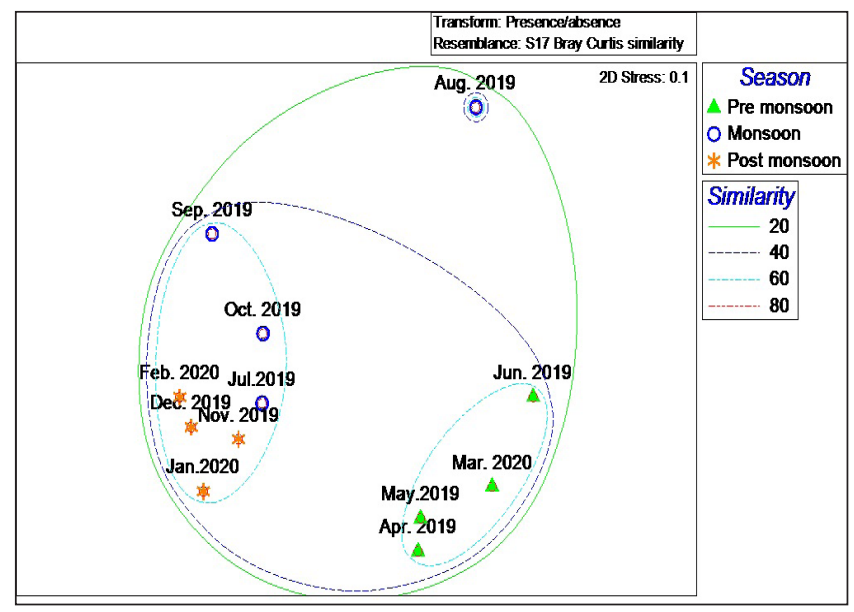

Fig. 7: MDS plot showing various similarity levels 
The purpose of MDS was to construct a "map" or configuration of the samples, in a specified number of dimensions, which attempts to satisfy all the conditions imposed by the rank (dis) similarity matrix. This was to recognize the interrelationship between the samples in a map. In non-metric multidimensional scaling, the BrayCurtis similarity was used to construct a map in which those having more similarity placed near and samples are having lower similarity far away. The stress value is indicating the goodness of the fit.

\section{Taxonomic distinctness tests (TAXDTEST)}

The $95 \%$ confidence funnel was created to find out the variation in taxonomic distinctness during different months and presented in Fig. 8.

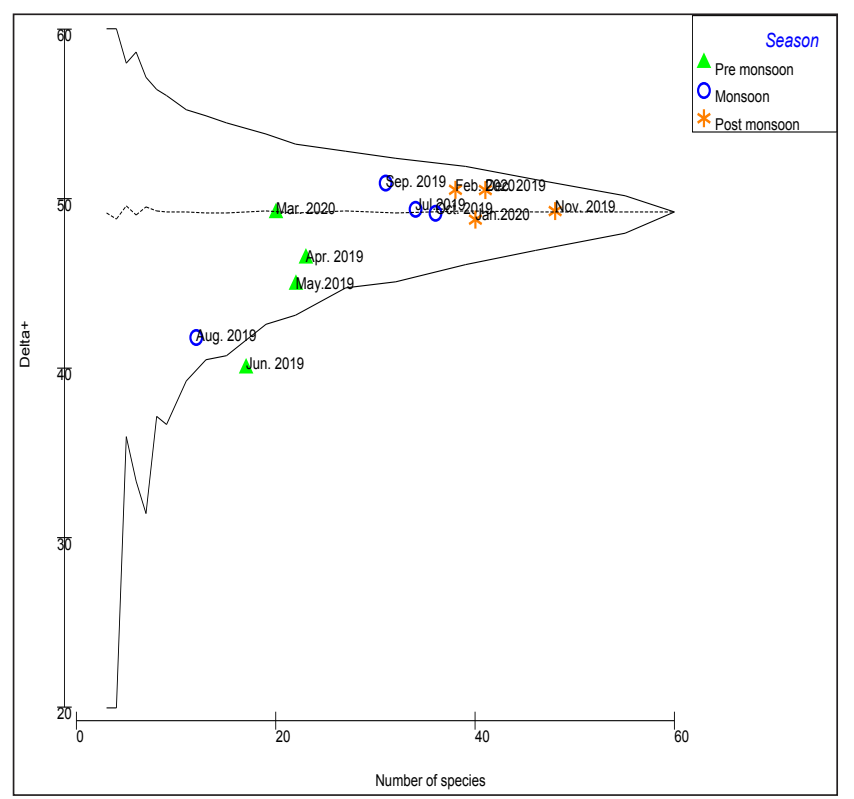

Fig. 8: The $95 \%$ confidence funnel for variation in taxonomic distinctness (lambda + )

The taxonomic distinctness values (lambda + ) fell within the confidence funnel and there was no deviation from the normal distribution except for the month of Jun. 2019 because of the less species richness. The same result also evident by ellipse plot (Fig. 9) drawn linking the average taxonomic distinctness and variation in taxonomic distinctness values, statistically significant departure of all months can be seen clearly with their percent similarity and dissimilarity in confidence funnel.

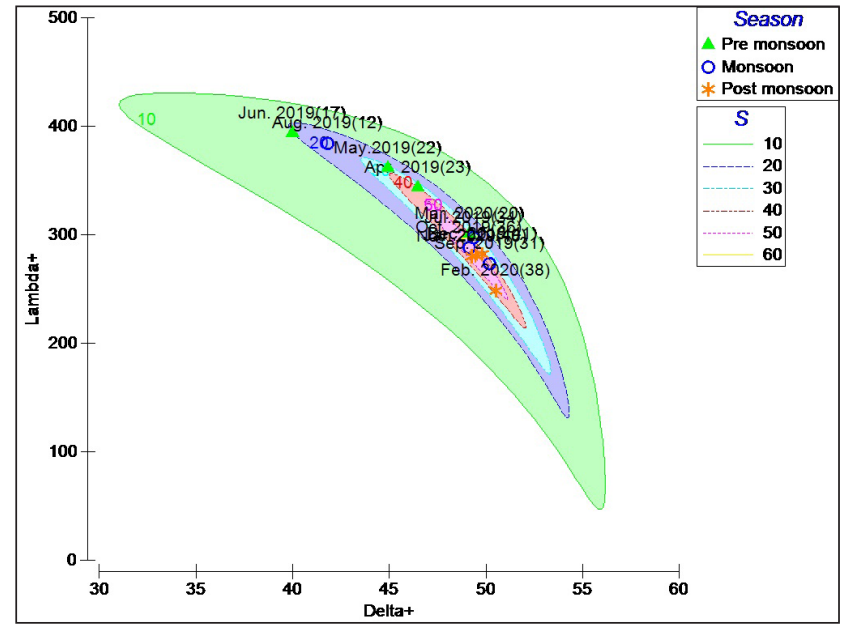

Fig. 9: Fitted 95\% probability contours of average taxonomic distinctness (delta +$)$ and variation in taxonomic distinctness $($ lambda + )

This test combining average taxonomic distinctness and variation in taxonomic distinctness involves plotting of the combination of these values by drawing the $95 \%$ probability contours (ellipse), which are advantageous in testing under the usual null hypothesis of random sampling from the master species list and superimposing the real values.

\section{CONCLUSION}

The results of the contemporaneous study revealed that the River Sutlej along district Ludhiana grip rich ichthyofauna and supports the existence of indigenous and exotic fishes despite the facts the water quality of the river Sutlej deteriorating in the region of Punjab as per the existing scenario. Due to an anthropogenic bustle in river Sutlej, there is huge loss. The present study provides a baseline database with respect to fish species composition and its seasonal distribution for planning effective conservation measures to obtain sustainable fish production. There is still need an indelible management strategy to conserve this inherent treasure for maintaining sustainability and species richness in river Sutlej.

\section{ACKNOWLEDGEMENTS}

The authors are grateful to Dean, College of Fisheries and Head, Dept. of Fisheries Resource Management, College of Fisheries, GADVASU, Ludhiana for providing 
all necessary support during investigation and field data collection.

\section{REFERENCES}

Andrew, K., Carlson, M., Fincel, J., Longhenry, C.M., Brian, D.S. and Graeb. 2016. Effects of Historic Flooding on Fishes and Aquatic Habitats in a Missouri River Delta. J. Freshwater Ecol., 31 (2): 271-288.

Anonymous. 2019. Need to Sanction Setting up of Sewage Treatment Plant in Ludhiana City to Ensure Cleanliness of Buddha Nullah, Tuesday, August 5, 2014. Lok Sabha Debates.

Bhatnagar, A., Yadav, A.S. and Neeru. 2016. Fish Diversity of Haryana and its Conservation Status. J Appl. Nat. Sci., 8 (2): $1022-1027$.

Clarke, K.R. and Gorley, R.N. 2006. PRIMER v5 User Manual/ Tutorial. Plymouth University, UK.

Dhillon, SS. and Kaur, H. 1996. Analytical Studies on the Aquatic Ecosystems of Punjab, Final Technical Report. Punjab State Council for Science and Technology, Chandigarh.

Dudgeon, D. 1992. Endangered Ecosystems: A Review of the Conservation Status of Tropical Asian Rivers. Hydrobiologia, 248: 167-191.

Froese, R. and Pauly, D. 2019. Fishbase. World Wide Web Electronic Publication. FishBase. https://www.fishbase.se/ search.php.

Hassan, S.S. 2016. Ichthyofauna and Other Species Diversity Including Characteristics of Water Quality in River Satluj in Punjab (India). Int. J. Eng. Technol. Manag. Appl. Sci., 4(6): 192.

Indiatoday. 2019. 209 Villages Evacuated in 3 Districts of Punjab. Indiatoday. https://www.indiatoday.in/mailtoday/story/209-villages-evacuated-in-3-districts-ofpunjab-1582140-2019-08-19.
Jaidka, A. and Hundal, S.S. 2016. Histological Changes in Gills and Liver of Fishes in River Sutlej as an Effect of Buddha Nullah Pollution at Ludhiana. Int. J. of Life Sci., 5 (1): 87-92.

Jayaram, K.C. 1981. The Freshwater Fishes of the Indian Region. Narendra Publishing House, New Delhi.

Johal, M.S. and Tandon, K.K. 1980. Monograph on the Fishes of Re-Organised Punjab. Part I. Punjab Fisheries Bulletin, 3: $1-44$.

Junk, WJ., Bayley, P.B. and Sparks, R.E. 1989. The flood-pulse concept in river-floodplain systems. In: Dodge, D.P., Ed., Proceedings of the International Large River Symposium (LARS), Can. J. Fish. Aquat. Sci., Special Publication, 106, NRC research press, Ottawa, 110-127.

Kaur, H., Datta, S.N. and Singh, A. 2017. Fish Catch Composition and Biodiversity Indices at Harike Wetland- A Ramsar Site in India. J. Anim. Res., 7(5): 935-941.

Kumar, J., Benakappa, S., Kumar, A.S.N. and Rawat, S. 2020. Seasonal Variation of Ichthyofauna in Trawling Grounds off Mangaluru Coast, Southwest Coast of India. Indian. J. Geo Mar. Sci., 49(3): 364-372.

The Hindu. 2019. Punjab on Alert after Release of Excess Water from Bhakra Dam. TheHindu. https://www. thehindubusinessline.com/economy/agri-business/bhakradam-level-crosses-permissible-limit-more-water-released/ article29153103.ece.

Warwick, M.R. 1986. A New Method for Detecting Pollution Effect on Benthic Communities. Mar. Biol., 92: 557-562. 
